\title{
Expression of MMP-9 and IL-6 in patients with subarachnoid hemorrhage and the clinical significance
}

\author{
LUCHEN WANG $^{1}$ and ZIYUN GAO ${ }^{2}$ \\ ${ }^{1}$ Department of Clinical Medicine, Queen Mary College of Nanchang University; ${ }^{2}$ Department of Neurosurgery, \\ The Second Affiliated Hospital of Nanchang University, Nanchang, Jiangxi 330000, P.R. China
}

Received July 11, 2017; Accepted November 14, 2017

DOI: $10.3892 / \mathrm{etm} .2017 .5553$

\begin{abstract}
The purpose of the present study was to investigate the expression of matrix metalloproteinase-9 (MMP-9) and interleukin-6 (IL-6) in patients with subarachnoid hemorrhage (SAH) and the clinical significance thereof. Forty-three patients with SAH and 23 healthy individuals were enrolled in this study. Patients were divided into the cerebral vasospasm (CVS) and non-cerebral vasospasm (non-CVS) groups, or the good and poor prognosis groups. Serum levels of MMP-9 and IL-6 were detected by ELISA. Expression levels of MMP-9 and IL- 6 mRNAs were detected by RT-qPCR. Expression levels of MMP-9 and IL-6 were elevated with the increase of grades as determined by the Hunt-Hess grading method. Serum levels of MMP-9 and IL-6 in the CVS and poor prognosis groups were significantly higher than those in the control group. Expression levels of MMP-9 and IL-6 in the CVS group were significantly higher than those in the non-CVS group $(\mathrm{P}<0.05)$. Compared with the good prognosis group, the expression levels of MMP-9 and IL-6 were significantly increased in the poor prognosis group at 1, 4, 7 and 10 days after $\mathrm{SAH}(\mathrm{P}<0.05)$. Additionally, the expression level of MMP-9 was significantly positively correlated with that of IL-6 $(\mathrm{P}<0.05)$. Expression levels of MMP-9 and IL-6 were significantly increased in patients with SAH, and the expression level of MMP-9 was positively correlated with that of IL-6. Thus, MMP-9 and IL-6 are involved in the development of SAH.
\end{abstract}

\section{Introduction}

Subarachnoid hemorrhage (SAH) is a syndrome whereby blood reaches subarachnoid space in brain or spinal canal after the rupture of intracranial vascular (1). It has been reported that SAH accounts for approximately $15 \%$ of cerebrovascular disease (2). Without effective treatment, bleeding can lead

Correspondence to: Dr Ziyun Gao, Department of Neurosurgery, The Second Affiliated Hospital of Nanchang University, 1 Minde Road, Nanchang, Jiangxi 330000, P.R. China

E-mail: gaozy077@163.com

Key words: subarachnoid hemorrhage, matrix metalloproteinase-9, interleukin-6 to the death of approximately $13 \%$ of patients $(3,4)$. SAH is usually followed by cerebral vasospasm (CVS) or even cerebral infarction in some extreme cases $(5,6)$. Thus, the early diagnosis of the disease is imperative.

An increasing number of researchers posit that SAH is closely associated with the inflammatory response in the body, and the development of SAH is correlated with the expression levels of cytokines in the body (7-10). As a type of gelatinase, MMP-9 was found to be involved in the development of a variety of neurological diseases. As an inflammatory factor, IL-6 is associated with the inflammatory stress state and vascular damage in the body.

In the present study, the expression levels of MMP-9 and IL-6 in patients with SAH were detected, and the correlation between them was also investigated to explore the pathogenesis of SAH in order to provide new insights for the clinical diagnosis of SAH.

\section{Materials and methods}

General information. Forty-three patients clinically diagnosed with SAH were selected from January, 2016 to May, 2017. The patients included 27 males and 16 females, with an age range of 57-66 years. Clinical data were sorted using the Hunt-Hess grading method and evaluated by a specialist. Exclusion criteria for the study were: Course of disease $>3$ days; patients that underwent treatment in other hospitals; patients with liver, renal, heart and lung dysfunction and infectious diseases. Normal controls comprised 23 healthy subjects including 13 males and 10 females, with an age range of 51-64 years. Patients were divided into the CVS and non-CVS groups. Patients were subdivided into the good or poor prognosis group according to APACHE II score. No significant differences in age and gender were found between normal healthy controls and patients with SAH $(\mathrm{P}>0.05)$.

Patients provided written informed consent. This study was approved by the Ethics Committee of the Second Affiliated Hospital of Nanchang University.

Experimental reagents. Human IL-6 ELISA kit (Genetimes Technology, Inc., Shanghai, China); human MMP-9 ELISA kit (Beijing Belife Bio-Medical Technology Ltd., Beijing, China); reverse transcription kit (Neobioscience, Shenzhen, China); RT-qPCR kit (Sci-MEDs, Wuhan, China); primers [Huamei 
Table I. Primer sequences.

\begin{tabular}{lc}
\hline Gene name & \multicolumn{1}{c}{ Primer sequences } \\
\hline MMP-9 & F: 5'- AAGGATGGTCTACTGGCAC-3' \\
& R: 5'- TCAGAACCGACCCTACAA-3' \\
IL-6 & F: 5'- GGCCCTTGCTTTCTCTTCG-3' \\
& R: 5'- ATAATAAAGTTTTGATTATGT-3' \\
GAPDH & F: 5'-TGGGTGTGAACCACGAGAA-3' \\
& R: 5'-GGCATGGACTGTGGTCATGA-3'
\end{tabular}

$\mathrm{F}$, forward; R, reverse.

Ruikang (Beijing) International Biotechnology Research Institute Co., Ltd., Beijing, China]; total RNA extraction kit (Yuanmu Biological Technology Co., Ltd., Shanghai, China) were used in the present study.

Detection of MMP-9 and IL-6 levels in serum. Venous blood $(5 \mathrm{ml})$ was extracted at 1, 4, 7 and 10 days after SAH. Blood samples were transferred to anticoagulant tubes, followed by centrifugation at 2,010 x g for $5 \mathrm{~min}$ to collect plasma. Plasma was stored at $-80^{\circ} \mathrm{C}$. The same amount of venous blood was also extracted from healthy controls to prepare plasma. Levels of MMP-9 and IL-6 were detected according to the instructions of the kit.

All the reagents in hte ELISA kit were kept at room temperature for $30 \mathrm{~min}$. Serum sample $(50 \mu \mathrm{l})$ and diluted standard were placed into the microwells. Three repeat wells were utilized. Enzyme conjugate $(50 \mu \mathrm{l})$ was added into each well except the control well. Liquid in microwells was mixed followed by incubation at $37^{\circ} \mathrm{C}$ for $30 \mathrm{~min}$. Reaction solution in microwells was discarded and the microwells were filled with washing solution. After washing, the microwells were dried and color developers A and B (50 $\mu$ l for each) were added and mixed, followed by incubation. Stop solution $(50 \mu \mathrm{l})$ was added and OD values at $450 \mathrm{~nm}$ were measured using a Sunrise microplate reader (Tecan, Männedorf, Switzerland). The standard curve was plotted and levels of MMP-9 and IL-6 in serum were measured.

RT-qPCR used to detect RNA expression. Primers were synthesized by Huamei Ruikang (Beijing) International Biotechnology Research Institute Co., Ltd. Primer sequences are listed in Table I. Total RNA was extracted from serum using a total RNA extraction kit according to the manufacturer's instructions. cDNA was synthesized using a reverse transcription kit.

Reaction solution (10 $\mu \mathrm{l})$ was obtained using $2 \mu \mathrm{l}$ 5X gDNA Eraser Buffer, $1 \mu \mathrm{l}$ gDNA Eraser, $1 \mu \mathrm{g}$ total RNA, and RNase-free $\mathrm{dH}_{2} \mathrm{O}$.

For the reverse transcription system $(20 \mu \mathrm{l}), 4 \mu \mathrm{l} 5 \mathrm{X}$ PrimeScript Buffer, $1 \mu$ l PrimeScipt RT Enzyme Mix, $1 \mu 1$ PrimeScript RT Enzyme Mix, $10 \mu$ l of reaction solution, and $4 \mu \mathrm{l}$ of RNase-free $\mathrm{dH}_{2} \mathrm{O}$ were used. Reverse transcription reaction conditions were: $37^{\circ} \mathrm{C}$ for $15 \mathrm{~min}$ and $85^{\circ} \mathrm{C}$ for $5 \mathrm{sec}$ (Table I).

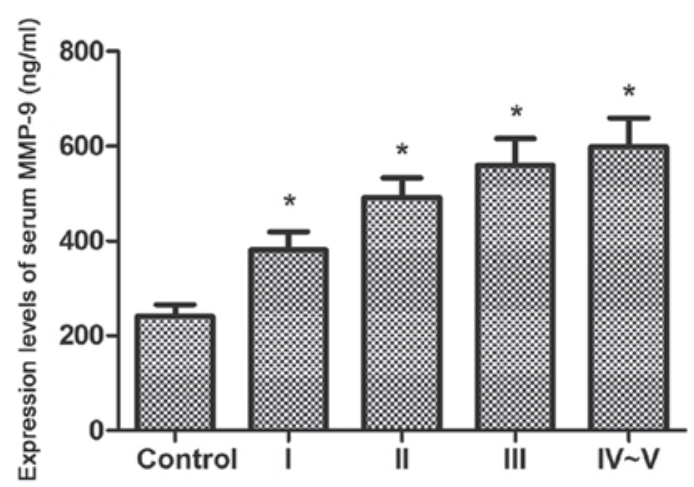

Figure 1. Expression levels of MMP-9 in serum of SAH patients with different Hunt-Hess grades. ELISA results showed significant differences between the control group and patients with different Hunt-Hess grades. ${ }^{*} \mathrm{P}<0.05$.

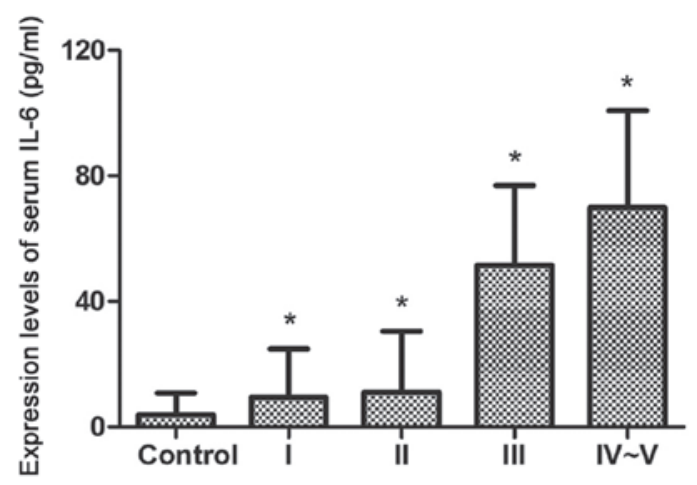

Figure 2. Expression levels of IL-6 in serum of SAH patients with different Hunt-Hess grades. ELISA results showed significant differences between the control group and patients with different Hunt-Hess grades. ${ }^{*} \mathrm{P}<0.05$.

For the PCR reaction system $(25 \mu \mathrm{l}), 12.5 \mu \mathrm{l}$ of SYBR Premix Ex Taq ${ }^{\mathrm{TM}}$ II, $1 \mu \mathrm{l}$ of forward primer, $1 \mu \mathrm{l}$ of reverse primer, $2 \mu \mathrm{l}$ of cDNA, and $8.5 \mu \mathrm{l}$ of $\mathrm{dH}_{2} \mathrm{O}$ were used. Reaction conditions were: $94^{\circ} \mathrm{C}$ for $3 \mathrm{~min}$, followed by 40 cycles of $94^{\circ} \mathrm{C}$ for $20 \mathrm{sec}$ (denaturation), $58^{\circ} \mathrm{C}$ for $20 \mathrm{sec}$ (annealing) and $72^{\circ} \mathrm{C}$ for $30 \mathrm{sec}$ (elongation). GAPDH was used as endogenous control. The relative expression levels of MMP-9 and IL-6 mRNA were calculated by RT-PCR instrument.

Statistical analysis. SPSS 17.0 (Mathematica, Beijing, China) statistical software was used for statistical analysis. Data were presented as mean \pm standard deviation. Single-factor analysis of variance was performed for comparisons among multiple groups. Pearson's analysis was used to test the correlation between the two factors, with signifcant differences at $\alpha=0.05$.

\section{Results}

Expression levels of MMP-9 and IL-6 in serum of SAH patients with different Hunt-Hess grades. Compared with the normal control group, the expression levels of MMP-9 and IL-6 were increased in serum of SAH patients with different HuntHess grades. In addition, significant differences were found between different Hunt-Hess grades $(\mathrm{P}<0.05)$. Expression levels of MMP-9 and IL-6 were elevated with the increase of Hunt-Hess grades (Figs. 1 and 2). 
Table II. Comparison of expression levels of MMP-9 between the CVS and non-CVS groups (mean \pm SD).

\begin{tabular}{lrllll}
\hline Groups & $\mathrm{N}$ & \multicolumn{1}{c}{1 day } & \multicolumn{1}{c}{4 days } & 7 days & 10 days \\
\hline Control group & 23 & $241.16 \pm 24.33$ & $241.16 \pm 24.33$ & $241.16 \pm 24.33$ & $241.16 \pm 24.33$ \\
CVS group & 35 & $382.06 \pm 24.17^{\mathrm{a}, \mathrm{b}}$ & $437.43 \pm 61.44^{\mathrm{a}, \mathrm{b}}$ & $501.19 \pm 59.74^{\mathrm{a}, \mathrm{b}}$ & $584.38 \pm 61.85^{\mathrm{a}, \mathrm{b}}$ \\
Non-CVS group & 8 & $315.29 \pm 28.91^{\mathrm{a}}$ & $382.37 \pm 55.03^{\mathrm{a}, \mathrm{c}}$ & $320.75 \pm 30.46^{\mathrm{a}}$ & $253.16 \pm 22.18$ \\
\hline
\end{tabular}

${ }^{\mathrm{a}} \mathrm{P}<0.05$, compared with normal control group; ${ }^{\mathrm{b}} \mathrm{P}<0.05$, compared with non-CVS group; ${ }^{\mathrm{c}} \mathrm{P}<0.05$, compared with 1,7 and 10 days .

Table III. Comparison of expression levels of IL-6 between the CVS and non-CVS groups (mean \pm SD).

\begin{tabular}{lrcccc}
\hline Groups & $\mathrm{N}$ & 1 day & 4 days & 7 days & 10 days \\
\hline Control group & 23 & $241.16 \pm 24.33$ & $241.16 \pm 24.33$ & $241.16 \pm 24.33$ & $241.16 \pm 24.33$ \\
CVS group & 35 & $50.12 \pm 21.37^{\mathrm{a}, \mathrm{b}}$ & $65.91 \pm 19.37^{\mathrm{a}, \mathrm{b}}$ & $77.19 \pm 25.37^{\mathrm{a}, \mathrm{b}}$ & $90.43 \pm 30.48^{\mathrm{a}, \mathrm{b}}$ \\
Non-CVS group & 8 & $31.07 \pm 14.75^{\mathrm{a}}$ & $55.19 \pm 19.34^{\mathrm{a}, \mathrm{c}}$ & $42.74 \pm 27.49^{\mathrm{a}}$ & $3.08 \pm 9.22$ \\
\hline
\end{tabular}

${ }^{\mathrm{a}} \mathrm{P}<0.05$, compared with normal control group; ${ }^{\mathrm{b}} \mathrm{P}<0.05$, compared with non-CVS group; ${ }^{\mathrm{c}} \mathrm{P}<0.05$, compared with 1,7 and 10 days.

Table IV. Comparison of expression levels of MMP-9 between the poor and good prognosis groups (mean \pm SD).

\begin{tabular}{lrcccc}
\hline Groups & $\mathrm{N}$ & \multicolumn{1}{c}{1 day } & 4 days & 7 days & 10 days \\
\hline Control group & 23 & $241.16 \pm 24.33$ & $241.16 \pm 24.33$ & $241.16 \pm 24.33$ & $241.16 \pm 24.33$ \\
Good prognosis group & 35 & $336.61 \pm 20.95^{\mathrm{a}}$ & $392.88 \pm 35.91^{\mathrm{a}, \mathrm{c}}$ & $355.73 \pm 30.92^{\mathrm{a}}$ & $301.27 \pm 28.49^{\mathrm{a}}$ \\
Poor prognosis group & 8 & $384.25 \pm 30.19^{\mathrm{a}, \mathrm{b}}$ & $466.92 \pm 31.06^{\mathrm{a}, \mathrm{b}}$ & $499.28 \pm 35.27^{\mathrm{a}, \mathrm{b}}$ & $582.36 \pm 41.94^{\mathrm{a}, \mathrm{b}}$ \\
\hline
\end{tabular}

${ }^{\mathrm{a}} \mathrm{P}<0.05$, compared with normal control group; ${ }^{\mathrm{b}} \mathrm{P}<0.05$, compared with good prognosis group; ${ }^{\mathrm{c}} \mathrm{P}<0.05$, compared with 1,7 and 10 days.

Table V. Comparison of expression levels of IL-6 between the poor and good prognosis groups (mean \pm SD).

\begin{tabular}{lccccc}
\hline Groups & $\mathrm{N}$ & 1 day & 4 days & 7 days & 10 days \\
\hline Control group & 23 & $241.16 \pm 24.33$ & $241.16 \pm 24.33$ & $241.16 \pm 24.33$ & $241.16 \pm 24.33$ \\
Good prognosis group & 26 & $28.99 \pm 13.27^{\mathrm{a}}$ & $48.85 \pm 17.91^{\mathrm{a}, \mathrm{c}}$ & $41.33 \pm 25.02^{\mathrm{a}}$ & $4.12 \pm 6.44^{\mathrm{a}}$ \\
Poor prognosis group & 17 & $46.24 \pm 19.05^{\mathrm{a}, \mathrm{b}}$ & $58.99 \pm 21.17^{\mathrm{a}, \mathrm{b}}$ & $70.35 \pm 28.47^{\mathrm{a}, \mathrm{b}}$ & $88.39 \pm 31.32^{\mathrm{a}, \mathrm{b}}$ \\
\hline
\end{tabular}

${ }^{\mathrm{a}} \mathrm{P}<0.05$, compared with normal control group; ${ }^{\mathrm{b}} \mathrm{P}<0.05$, compared with good prognosis group; ${ }^{\mathrm{P}} \mathrm{P}<0.05$, compared with 1,7 and 10 days.

Expression of MMP-9 and IL-6 in serum of the CVS and non-CVS groups. Compared with the normal control group, the expression levels of MMP-9 and IL-6 in the CVS and non-CVS groups were significantly increased, and the expression levels were significantly higher in the CVS group than those in the non-CVS group $(\mathrm{P}<0.05)$. In the CVS group, expression levels of MMP-9 and IL-6 in serum were gradually increased with the prolongation of time. In the non-CVS group, the expression levels of MMP-9 and IL-6 reached the peak at 4 days after SAH, and gradually decreased after that. In the CVS group, significant differences in the expression levels of MMP-9 and IL-6 in serum were found between different time points (1, 4, 7 and 10 days after $\mathrm{SAH})$. In the non-CVS group, the expression levels of MMP-9 and IL-6 at
4 days were significantly different those at 1,7 and 10 days (Tables II and III).

Expression of MMP-9 and IL-6 in serum of the poor and good prognosis groups. Compared with the control group, the expression levels of MMP-9 and IL-6 in serum of the poor and good prognosis groups were significantly increased at 1, 4, 7 and 10 days after $\mathrm{SAH}(\mathrm{P}<0.05)$. Compared with the good prognosis group, the expression levels of MMP-9 and IL-6 in serum of the poor prognosis group were significantly increased at 1, 4, 7 and 10 days after SAH $(\mathrm{P}<0.05)$. In the poor prognosis group, the expression levels of serum MMP-9 and IL-6 were gradually increased. In the good prognosis group, the expression levels of serum MMP-9 and IL-6 reached the peaks at 4 days, and 


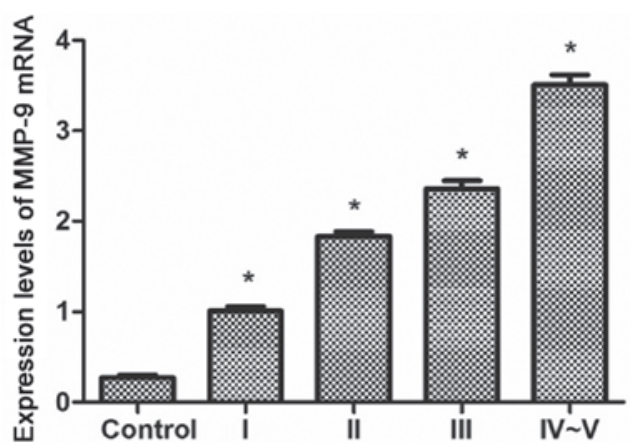

Figure 3. Expression of MMP-9 mRNA. ELISA results showed a significant difference between patients with different Hunt-Hess grades and normal controls. ${ }^{*} \mathrm{P}<0.05$.

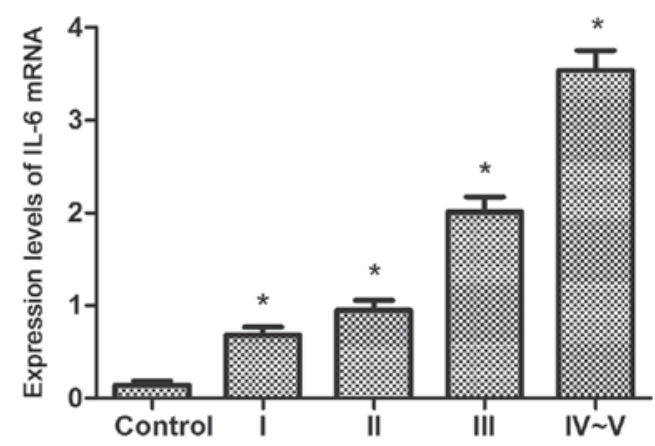

Figure 4. Expression of IL-6 mRNA. ELISA results showed a significant difference between patients with different Hunt-Hess grades and normal controls. ${ }^{*} \mathrm{P}<0.05$.

gradually decreased after that. In the poor prognosis group, significant differences in the expression levels of MMP-9 and IL-6 in serum were found between different time points (1, 4, 7 and 10 days after SAH). In the good prognosis group, the expression levels of MMP-9 and IL-6 at 4 days were significantly different those at 1, 7 and 10 days (Tables IV and V).

mRNA expression detected by RT-qPCR.Melting curves of the $P C R$ reactions showed single peaks, indicating the high specificity of primers. Compared with the normal control group, the expression levels of MMP-9 and IL-6 were significantly increased in serum of patients with different SAH Hunt-Hess grades $(\mathrm{P}<0.05)$. Expression levels of MMP-9 and IL-6 were elevated with the increase of SAH Hunt-Hess grades, and significant differences were identified between the patients with different SAH Hunt-Hess grades (Figs. 3 and 4).

Correlation between the expression of MMP-9 and IL-6. Pearson's correlation analysis was performed to explore the correlation between the expression of MMP-9 and IL-6. A significant positive correlation was found $(\mathrm{r}=0.583, \mathrm{P}<0.05)$. Thus, expression levels of MMP-9 and IL- 6 were increased after inflammation and were positively correlated with each other.

\section{Discussion}

SAH is a syndrome whereby blood reaches subarachnoid space in brain or spinal canal after the rupture of intracra- nial vascular. SAH has a high mortality $(11,12)$. As a kind of gelatinase, MMP-9 is usually considered a form of zymogen, and many cells in brain can secrete MMP-9 zymogen $(13,14)$. Activation of the zymogen can lead to the degradation of extracellular matrix in brain (15). It has been reported that the expression of MMP-9 and VEGF after SAH can be used to predict the occurrence of delayed CVS. MMP-9 expression levels in serum of patients with SAH was increased, indicating that MMP-9 expression was correlated with SAH $(16,17)$. As a glycoprotein, IL-6 can participate in collective inflammatory response and anti-infective defense $(18,19)$. IL-6 is a multi-functional glycoprotein cell inflammatory factor that is involved in various inflammatory reactions of the central nervous system. IL- 6 can also trigger the immune response in the body to respond to brain damage and inflammation (20).

In this study, the expression levels of MMP-9 and IL-6 in serum of 43 patients with SAH were detected. Results showed that, compared with the normal control group, the expression levels of MMP-9 and IL-6 were increased in serum of SAH patients with different Hunt-Hess grades. In addition, significant differences were found between different Hunt-Hess grades. Expression levels of MMP-9 and IL-6 were elevated with the increase of Hunt-Hess grades. Compared with the normal control group, the expression levels of MMP-9 and IL-6 in the CVS and non-CVS group were significantly increased at 1, 4, 7 and 10 days after $\mathrm{SAH}$, and the expression levels were significantly higher in the CVS group than in the non-CVS group. In the CVS group, the expression levels of MMP-9 and IL-6 in serum were gradually increased with the prolongation of time. Expression levels of MMP-9 and IL- 6 reached the peak at 4 days after SAH, and gradually decreased after that. Compared with the control group, the expression levels of MMP-9 and IL-6 in serum of the poor and good prognosis groups were significantly increased at 1, 4, 7 and 10 days after SAH. Compared with the good prognosis group, the expression levels of MMP-9 and IL-6 in serum of the poor prognosis group were significantly increased at 1, 4, 7 and 10 days after SAH. In the poor prognosis group, the expression levels of serum MMP-9 and IL-6 were gradually increased. In the good prognosis group, the expression levels of serum MMP-9 and IL-6 reached the peaks at 4 days, and gradually decreased after that. Compared with the normal control group, the expression levels of MMP-9 and IL- 6 were significantly increased in serum of patients with different SAH Hunt-Hess grades. Expression levels of MMP-9 and IL-6 were increased with the increase of SAH Hunt-Hess grades, and significant differences were found between patients with different SAH Hunt-Hess grades. In SAH patients, MMP-9 expression was positively correlated with the expression level of IL-6. It was confirmed that the expression of MMP-9 and IL-6 in serum of patients with $\mathrm{SAH}$ reflected the severity and development of inflammatory reaction. Both MMP-9 and IL-6 were involved in the development of SAH and CVS, and prognosis.

In conclusion, the expression levels of MMP-9 and IL-6 in serum of patients with SAH were detected. The expression levels of MMP-9 and IL-6 were positively correlated with each other. Expression levels of MMP-9 and IL-6 can reflect the development of SAH, and the expression of MMP-9 and IL-6 is of clinical significance in the diagnosis of SAH. 


\section{References}

1. Pan P, Zhang X, Li Q, Zhao H, Qu J, Zhang JH, Liu X, Feng H and Chen Y: Cyclosporine A alleviated matrix metalloproteinase 9 associated blood-brain barrier disruption after subarachnoid hemorrhage in mice. Neurosci Lett 649: 7-13, 2017.

2. Zhang XS, Zhang X, Zhang QR, Wu Q, Li W, Jiang TW and Hang CH: Astaxanthin reduces matrix metalloproteinase-9 expression and activity in the brain after experimental subarachnoid hemorrhage in rats. Brain Res 1624: 113-124, 2015

3. Lago A, Tembl JI, López-Cuevas R, Vallés J, Santos MT, Moscardó A and Parkhutik V: Characterisation of DWI-MRI confirmed cerebral infarcts in patients with subarachnoid haemorrhage and their association with MMP-9 levels. Neurol Res 37: 688-692, 2015.

4. Wu W, Guan Y, Zhao G, Fu XJ, Guo TZ, Liu YT, Ren XL, Wang W, Liu HR and Li YQ: Elevated IL-6 and TNF- $\alpha$ levels in cerebrospinal fluid of subarachnoid hemorrhage patients. Mol Neurobiol 53: 3277-3285, 2016

5. Wang Z, Meng CJ, Shen XM, Shu Z, Ma C, Zhu GQ, Liu HX, He WC, Sun XB, Huo L, et al: Potential contribution of hypoxiainducible factor-1 $\alpha$, aquaporin- 4 , and matrix metalloproteinase-9 to blood-brain barrier disruption and brain edema after experimental subarachnoid hemorrhage. J Mol Neurosci 48: 273-280, 2012.

6. Dang B, Shen H, Li H, Zhu M, Guo C and He W: Matrix metalloproteinase 9 may be involved in contraction of vascular smooth muscle cells in an in vitro rat model of subarachnoid hemorrhage. Mol Med Rep 14: 4279-4284, 2016.

7. Ding W, Gao N, Li MX, Ding LJ, Li FF and Mou L: Clinical evaluation of the efficacy of the combination of aneurysm embolization and cerebrospinal fluid replacement in the treatment of aneurysmal subarachnoid hemorrhage. Eur Rev Med Pharmacol Sci 19: 402-405, 2015.

8. Wostrack M, Reeb T, Martin J, Kehl V, Shiban E, Preuss A, Ringel F, Meyer B and Ryang YM: Shunt-dependent hydrocephalus after aneurysmal subarachnoid hemorrhage: The role of intrathecal interleukin-6. Neurocrit Care 21: 78-84, 2014.

9. Adamczyk P, He S, Amar AP and Mack WJ: Medical management of cerebral vasospasm following aneurysmal subarachnoid hemorrhage: A review of current and emerging therapeutic interventions. Neurol Res Int 2013: 462491, 2013.

10. Kim JH, Kim JH, Kim SC, Yi YS, Yang WS, Yang Y, Kim HG, Lee JY, Kim KH, Yoo BC, et al: Adenosine dialdehyde suppresses MMP-9-mediated invasion of cancer cells by blocking the Ras/ Raf-1/ERK/AP-1 signaling pathway. Biochem Pharmacol 86: 1285-1300, 2013.
11. Yu LL, Liu YJ, Wang ZH, Shi L and Liu LX: The study of endogenous hepatocyte growth factor in the pathogenesis of intracranial aneurysms. Eur Rev Med Pharmacol Sci 21: 1176, 2017.

12. Egashira Y, Zhao H, Hua Y, Keep RF and Xi G: White matter injury after subarachnoid hemorrhage: Role of blood-brain barrier disruption and matrix metalloproteinase-9. Stroke 46: 2909-2915, 2015.

13. Muroi C, Seule M, Sikorski C, Dent W and Keller E: Systemic interleukin-6 levels reflect illness course and prognosis of patients with spontaneous nonaneurysmal subarachnoid hemorrhage. Acta Neurochir Suppl 115: 77-80, 2013.

14. Kurogi R, Kikkawa Y, Matsuo S, Nakamizo A, Mizoguchi M and Sasaki T: Upregulation of tissue inhibitor of metalloproteinase-1 contributes to restoration of the extracellular matrix in the rabbit basilar artery during cerebral vasospasm after subarachnoid hemorrhage. Brain Res 1616: 26-36, 2015.

15. Höllig A, Thiel M, Stoffel-Wagner B, Coburn M and Clusmann H: Neuroprotective properties of dehydroepiandrosterone-sulfate and its relationship to interleukin 6 after aneurysmal subarachnoid hemorrhage: A prospective cohort study. Crit Care 19: 231, 2015.

16. Li Z, Liang G, Ma T, Li J, Wang P, Liu L, Yu B, Liu Y and Xue Y: Blood-brain barrier permeability change and regulation mechanism after subarachnoid hemorrhage. Metab Brain Dis 30: 597-603, 2015

17. Chen T, Wang W, Li JR, Xu HZ, Peng YC, Fan LF, Yan F, $\mathrm{Gu} \mathrm{C}$, Wang L and Chen G: PARP inhibition attenuates early brain injury through NF- $\mathrm{B} / \mathrm{MMP}-9$ pathway in a rat model of subarachnoid hemorrhage. Brain Res 1644: 32-38, 2016.

18. Kundu S, Pushpakumar SB, Tyagi A, Coley D and Sen U: Hydrogen sulfide deficiency and diabetic renal remodeling: Role of matrix metalloproteinase-9. Am J Physiol Endocrinol Metab 304: E1365-E1378, 2013.

19. Niwa A, Osuka K, Nakura T, Matsuo N, Watabe $T$ and Takayasu M: Interleukin-6, MCP-1, IP-10, and MIG are sequentially expressed in cerebrospinal fluid after subarachnoid hemorrhage. J Neuroinflammation 13: 217, 2016.

20. Cao S, Zhu P, Yu X, Chen J, Li J, Yan F, Wang L, Yu J and Chen G: Hydrogen sulfide attenuates brain edema in early brain injury after subarachnoid hemorrhage in rats: Possible involvement of MMP-9 induced blood-brain barrier disruption and AQP4 expression. Neurosci Lett 621: 88-97, 2016.

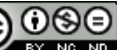

This work is licensed under a Creative Commons Attribution-NonCommercial-NoDerivatives 4.0 International (CC BY-NC-ND 4.0) License. 